\title{
Determination of Extended Fuzzy TOPSIS Method of Criteria Leading to Supplier Selection for Industries
}

\author{
Seyedhadi Eslamian Shiraz ${ }^{1,3}$, Ümran Şengül ${ }^{2} \&$ Miraç Eren $^{3}$ \\ ${ }^{1}$ Department of Management, Faculty of Humanities, University College of Nabi Akram (UCNA), Tabriz, Iran \\ ${ }^{2}$ Department of Econometrics, Faculty of Economics and Administrative Sciences, Çanakkale Onsekiz Mart \\ University, Terzioğlu Kampüsü, Çanakkale, Turkey \\ ${ }^{3}$ Department of Econometrics, Faculty of Economics and Administrative Sciences, Atatürk University, Erzurum, \\ Turkey \\ Correspondence: Seyedhadi Eslamian Shiraz, Department of Management, Faculty of Humanities, University \\ College of Nabi Akram (UCNA), Tabriz, No. 1283, Rah Ahan Street, Iran. Tel: 98-41-1442-1999. E-mail: \\ hadi.eslamian@gmail.com
}

\author{
Received: November 25, 2013 Accepted: December 24, 2013 Online Published: January 26, 2014 \\ doi:10.5539/ass.v10n4p183 URL: http://dx.doi.org/10.5539/ass.v10n4p183
}

\begin{abstract}
Supplier selection decisions require the choices of individual purchases to determine products and order quantities from certain suppliers. When suppliers are evaluated according to well-defined criteria, their level of effort and attention to detail is expected to increase significantly. This can provide to improve productivity. So, determination of supplier selection criteria that is a multi-criteria decision making process can include both quantitative and qualitative elements that are very important. In this article, the aim is to offer a fuzzy decision making method to determine leading criteria, in terms of supplier selection for an automobile company that operates in Iran, because the right suppliers that are selected according to well-defined criteria can significantly reduce the material purchasing costs and improve corporate competitiveness. For that purpose, linguistic values are used for expressing fuzzy numbers in order to assess the ratings and weights of these factors by considering criteria such as the decisions made by people who work in the purchasing department of the company. Afterward, the fuzzy TOPSIS method that is a multiple criteria decision making (MCDM) method according to fuzzy set theory is presented to cope with the determination of supplier selection criteria process. According to the results, it is determined that the following are important for supplier selection criteria for automobile firms: delivery, the amount of past business, reciprocal arrangements, warranties, and geographical location.
\end{abstract}

Keywords: multi criteria decision making, fuzzy TOPSIS, supplier selection

\section{Introduction}

The automotive industry includes all of the companies in a wide range, and corporations related to the design, production, marketing, and selling of motor vehicles, motorcycles, towing vehicles. It is one of the world's most important economic sectors with its revenue. This sector may further enhance its manufacturing performance by identifying a well-defined set of criteria to select and assess suppliers to increase its sale, job creation, and profitability. Thus, suppliers also learn how to share knowledge, cooperate, and achieve success.

Supplier selection decisions require the preferences of individual purchasers to determine products and order quantities from selected vendors. Selecting right suppliers considerably improve corporate competitiveness and reduce the material purchasing cost that is why researchers trust that the vendor selection is the important tasks of a purchasing unit. (Dobler, Burt, \& Lee, 1990; Li, Fun, \& Hung, 1997; Xia \& Wu, 2007).

Most firms believe that is an essential part of their vendor selection process of being at the forefront of the use of vendor selection criteria. Organizations use vendor selection criteria to reinforce their selection process in order for making more effective relationships with suppliers. (Vonderembse \& Tracey, 1999). Many variables affect a supplier's performance. Twenty-three criteria that have been considered by buying authorities in different vendor selection processes are specified by Dickson (1966).

An important view of the purchasing is the vendor selection process which includes the acquisition of needed services, material, and facilities for all types of commerce. The first stage in any supplier evaluation procedure is 
to create the criteria required for supplier selection. In the literature, there is no further work on the selection criteria. However, some studies are as follows: Weber et al. $(1991,1993)$ categorize different articles linked to vendor selection and addressed the effect of just in time (JIT) production strategy in vendor selection. They noted that quality, delivery, and net price had been discussed in eighty percent, fifty-nine percent, and 54 percent, respectively within the seventy-four articles that use twenty-three criteria determined by Dickson. Yahya and Kingsman (1999) researched the furniture industry in Malaysia and used Dickson's vendor selection criteria (Dickson, 1966). Fawcet et al. (1997) submitted a measurement of the firm's logistics performance related to main variables, such as innovation, flexibility, delivery, quality and cost. Because of there are many various criteria for a good partner, this is not an easy decision. The criteria that enable the development of a partnership with the organization which is a member of a supply chain are usually guided by cost efficiency, the expectation of quality, volume flexibility, customer service, and delivery dependability (Li et al., 1997; Motwani et al., 1998; Olhager \& Selldin, 2004). Different corporations may have specific provisions related to supplier evaluation. For instance, functions of supplier logistics performance evaluation within the automotive sector in Europe include clarification and strategy formulation, management information, communication, motivation of vendors, alignment and coordination, priority and decision making. (Schmitz \& Platts, 2004).

In essence, as mentioned previously, the vendor selection process in the SCM system is a group decision making effort with multiple criteria. The numbers of decision makers, the degree of uncertainty, and the character of the criteria should be considered regarding this process. A review by Chai, Liu, and Ngai (2012) on the selection of suppliers indicated that the most frequently used technique is AHP (24.39 percent), followed by Lineer Programming (15.44 percent), TOPSIS (14.63 percent), Analytic Network Process (12.20 percent), DEA (10.57 percent), and multi-objective optimization (10.57 percent). TOPSIS may offer the basis for developing vendor selection methods. For example, if any two alternatives depend to the same floor of evaluation status, the closest coefficient value determined by TOPSIS can be used to determine the rank. Therefore, this method was utilized for determination of supplier selection criteria.

This article is formed as follows. The first part presents the basic descriptions and linguistic variables and notations of the fuzzy numbers. Afterwards, a fuzzy decision making model to give with a ranking of criteria used in the selection of suppliers is discussed. Then, the suggested method is painted with an example. Eventually, some conclusions are expressed at the end of this article.

\section{Method}

\subsection{Multiple-Criteria Decision Making}

Multi criteria decision making is a strong technique widely used for evaluation process including multiple inconsistent criteria. In addition, because it is at the forefront of personal judgments for partner selection and evaluation, the fuzzy approach is used (Büyüközkan, Feyzioğlu, \& Nebol, 2008; Paksoy, Pehlivan, \& Kahraman, 2012).

Natural language to explicit judgment or perception is ever intellectual, hesitant, or obscure (Wang \& Chang, 2007). Fuzzy set theory that is associated with processes of vagueness, and introduced by Zadeh (1965) has been applied to incorporate vague data into a decision making frame. Many approach has been presented for the fuzzy MCDM with the decision maker's priority data fully known and unknown (Kahraman, Ates, Çevik, Gülbay, \& Erdogan, 2007). The fuzzy TOPSIS method also is one of these.

This article tries to rank the criteria apply in the selection of vendors as an MCDM process by presenting a simple and selective approach. Further, because intellectual attentions are relating to ranking criteria and the decision, a fuzzy logic approach is accepted. Also in this study, each criteria determined by Dickson for supplier selection was considered as one alternative by experts, and the best ranking and selection has been made, taking into account that experts working in the purchasing department will have equal weight at the point of decision. So, this study is different from other studies of MCDM, because it is considered not as a decision of each expert, but as the decision criteria of all of them.

\subsection{Fuzzy Numbers}

Because human judgments containing preferences are often misty, they cannot be measured with an exact numerical value. Therefore, crisp data are insufficient to model real life conditions. The ranks and weights of the criteria determined by linguistic variables instead of numerical values may be a more pragmatic approach. (Bellman \& Zadeh, 1970; Chen, 2000, 2001; Delgado, Verdegay, \& Vila, 1992; Hsu \& Chen, 1997; Zadeh, 1975). A factor whose values are imparted in linguistic terms is referred as a linguistic variable. (Zimmermann, 2001). Linguistic variables are quite useful related to conditions that are not well specified to be wisely explained in 
known quantitative expression, being too complex (Zimmermann, 2001). For example, weight whose values are very low, low, medium ... etc. is a linguistic variable. Fuzzy numbers can also display these linguistic values.

In the following review, there are some essential descriptions of fuzzy sets (Buckley, 1985; Chen, 2000; Kaufmann, Gupta, \& Kaufmann, 1985; Negi, 1989; Zadeh, 1965, 1975; Zimmermann, 2001). The essential descriptions below will be applied throughout the article.

\section{Definition 1.1}

A fuzzv set $A$ in a universe of $X$ is determined bv a membership function $u_{\mathrm{A}}(x)$ that associates with each element $\mathrm{x}$ in $\mathrm{X}$ an actual number in the distance [0,1]. The function value $\mu_{\mathrm{A}}(x)$ is called the degree of membership of $\mathrm{x}$ in $A$ (Zadeh, 1965).

\section{Definition 1.2}

A fuzzy set $A$ of the universe of discourse $X$ is convex, if and only if for all $x_{1}, x_{2}$ in $X$,

$$
\mu_{\mathrm{A}}\left(\lambda x_{1}+(1-\lambda) x_{2}\right) \geq \min \left(\mu A\left(x_{1}\right), \mu A\left(x_{2}\right)\right)
$$

where $\lambda \in[0,1]$.

Definition 1.3

A fuzzy set $A$ of the universe of discourse $X$ is called a normal fuzzy set implying that

$$
\exists x_{i} \in X, \mu_{A}\left(x_{i}\right)=1
$$

Definition 1.4

A fuzzy number is a fuzzy subset in the universe of $X$ that is both convex and normal. Figure 1 shows a fuzzy $\tilde{n}$ number of the universe of discourse $X$, which is both convex and normal.

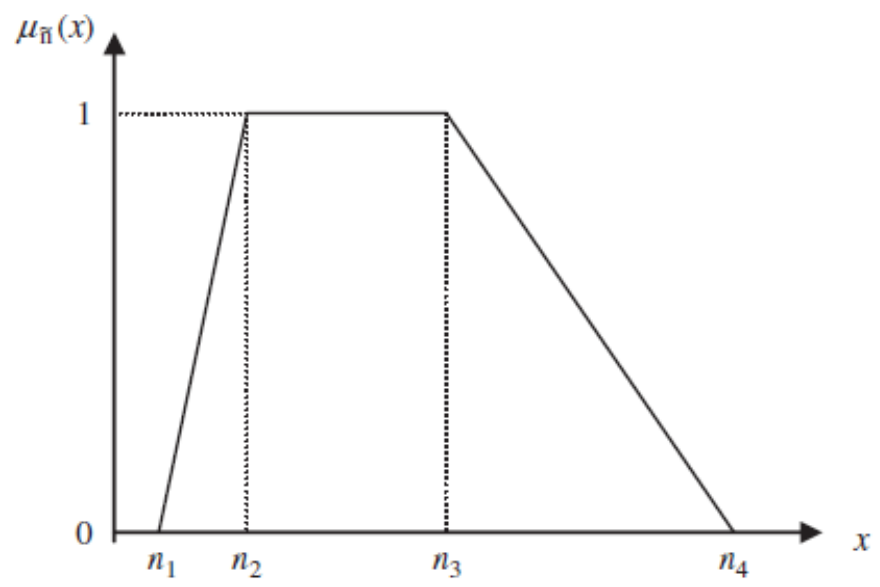

Figure 1. Trapezoidal fuzzy number $\tilde{n}$

\section{Definition 1.5}

A positive trapezoidal fuzzy number (PTFN) $\tilde{n}$ can be defined as $\left(\mathrm{n}_{1}, \mathrm{n}_{2}, \mathrm{n}_{3}, \mathrm{n}_{4}\right)$ shown in Figure 1.

The membership function, $\mu_{\mathrm{A}}(x)$ is defined as (Kaufmann et al., 1985). 


$$
\mu_{\tilde{n}}(x)= \begin{cases}0, & x<n_{1} \\ \frac{x-n_{1}}{n_{2}-n_{1}}, & n_{1} \leq x \leq n_{2} \\ 1, & n_{2} \leq x \leq n_{3} \\ \frac{x-n_{4}}{n_{4}-n_{3}}, & n_{3} \leq x \leq n_{4} \\ 0, & x>n_{4}\end{cases}
$$

For a trapezoidal fuzzy number $\tilde{n}=\left(\mathrm{n}_{1}, \mathrm{n}_{2}, \mathrm{n}_{3}, \mathrm{n}_{4}\right)$, if $\mathrm{n}_{2}=\mathrm{n}_{3}$, then $\mu_{\mathrm{A}}(x)$ is called a triangular fuzzy number.

A non-fuzzy number $r$ can be expressed as (r, r, r, r) (Chen, Lin, \& Huang, 2006).

\subsection{The Fuzzy TOPSIS Method}

A principled approach to develop the TOPSIS method is proposed to solve the supplier selection criteria process under a fuzzy environment. In this article, the ranking of qualitative criteria is intended as linguistic variables. Whether linguistic evaluations just proximate the intellectual judgment of decision makers, trapezoidal membership functions can be considered to be proportionate for receiving the ambiguity of these linguistic assessments (Chen et al., 2006; Delgado, Herrera, Herrera-Viedma, \& Martínez, 1998; Herrera \& Herrera-Viedma, 1996, 2000). It was considered a criterion that experts made the assessment by handling it as an alternative to the criteria used in the selection of suppliers. It was taken into equal weights for assessing, due to being on an equal level with experts who were responsible in the purchasing department of a company. According to this, it is proposed that the decision makers use the linguistic variables shown in Figure 2 to evaluate the importance of the supplier selection criteria. It was based on Chen's (2006) article for this scoring system.

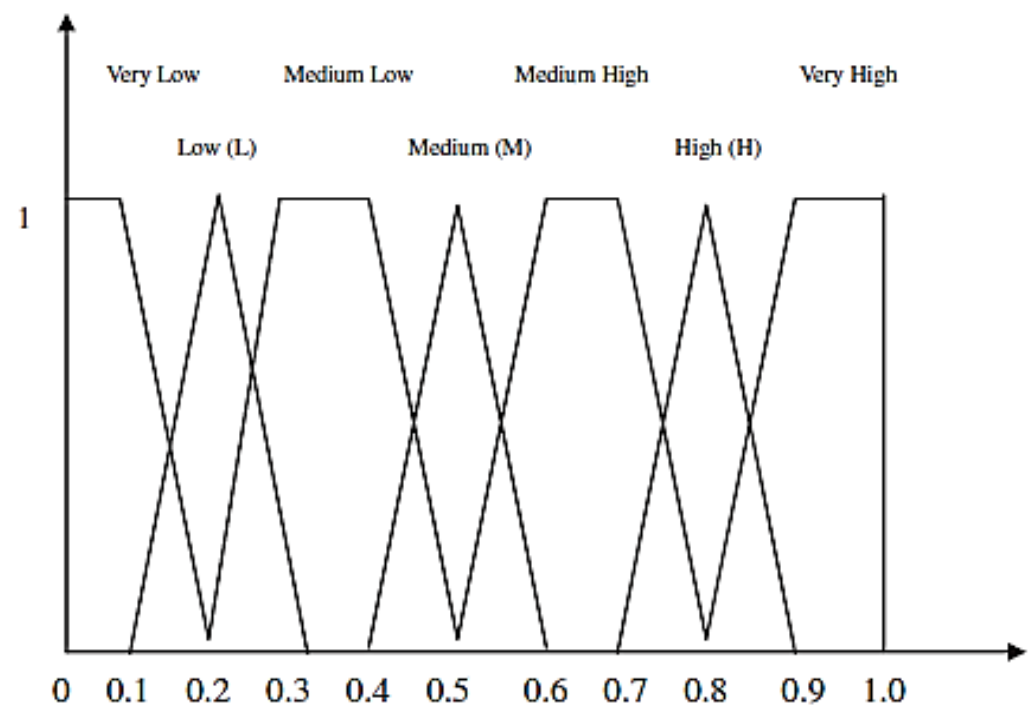

Figure 2. Linguistic variables for the importance of weight of each criteria

Fuzzy rankings $\left(x_{i j}\right)$ of alternatives with respect to each criterion can be calculated as

$$
\tilde{x}_{i j}=\left(a_{i j}, b_{i j}, c_{i j}, d_{i j}\right)
$$


Fuzzy weights $\left(w_{i j}\right)$ of each criterion can be calculated as

$$
\tilde{w}=\left(w_{i 1}, w_{i 2}, w_{i 3}, w_{i 4}\right)
$$

Here, $w_{i j}$ weights are equally taken into account for all $j=1,2, \ldots, n$ decision makers.

As stated above, the process of determining the criteria based on supplier selection can be concisely expressed in matrix format as follows:

$$
\widetilde{D}=\left[\begin{array}{cccc}
\tilde{x}_{11} & \tilde{x}_{12} & \cdots & \tilde{x}_{1 n} \\
\tilde{x}_{21} & \tilde{x}_{22} & \cdots & \tilde{x}_{2 n} \\
\vdots & \vdots & \cdots & \vdots \\
\tilde{x}_{m 1} & \tilde{x}_{m 2} & \cdots & \tilde{x}_{m n}
\end{array}\right], \quad \tilde{\mathrm{W}}=\left[\tilde{w} 1, \tilde{w} 2, \ldots, \tilde{w}_{n}\right]
$$

$$
\tilde{v}_{\mathrm{L}}=\tilde{w}_{2}=\ldots=\tilde{w}_{n} \text { Experts assume that the } \mathrm{e}
$$

1985), where $x_{i j}=\left(a_{i j}, b_{i j}, c_{i j}, d_{i j}\right) ; i=1,2, \ldots, m, j=1,2, \ldots, n$ can be approximated by positive trapezoidal fuzzy numbers. Here, the linear scale transformation is preferred to transform the various criteria scales into comparable scales. Thereby, it is prevented from the complexity of mathematical operations in a decision process. The set of criteria can be divided into two as benefit criteria (the higher the rating, the greater the preference) and cost criteria (the lower the rating, the greater the preference). Therefore, the normalized fuzzy-decision matrix can be represented as

$$
\widetilde{R}=\left[\widetilde{r}_{i j}\right]_{m \times n}
$$

where $\mathrm{B}$ and $\mathrm{C}$ are the sets of benefit criteria and cost criteria, respectively, and

$$
\begin{aligned}
& \tilde{r}_{i j}=\left(\frac{a_{i j}}{d_{j}^{*}}, \frac{b_{i j}}{d_{j}^{*}}, \frac{c_{i j}}{d_{j}^{*}}, \frac{d_{i j}}{d_{j}^{*}}\right), j \in B, \\
& \tilde{r}_{i j}=\left(\frac{a_{j}^{-}}{d_{i j}}, \frac{a_{j}^{-}}{c_{i j}}, \frac{a_{j}^{-}}{b_{i j}}, \frac{a_{j}^{-}}{a_{i j}}\right), j \in C, \\
& \tilde{d}_{j}=\max _{i} d_{i j}, j \in B, \\
& \tilde{a}_{j}=\min _{i} a_{i j}, j \in C,
\end{aligned}
$$

The normalization method mentioned above is designed to preserve the property in which the elements $\tilde{r i} j, \forall i, j$ are standardized (normalized) trapezoidal fuzzy numbers.

Considering the different importance of each criteria, the weighted normalized fuzzy-decision matrix is constructed as

$$
\tilde{\mathrm{V}}=\left[\tilde{v}_{i j}\right]_{m \times n}, i=1,2, \ldots, m ; j=1,2, \ldots, n
$$

where $\tilde{v_{i j}}=\tilde{r_{i j}}(.) \tilde{w}_{i j}$,

It is, because it was initially received as $\tilde{w_{1}}=\tilde{w}_{2}=\ldots=\tilde{w}_{n}$. 
According $R=V$ to the weighted normalized fuzzy-decision matrix, normalized positive trapezoidal fuzzy numbers can also approximate the elements $\tilde{v_{i j}}, \forall i, j$. Then, the fuzzy positive-ideal solution (FPIS, $A^{*}$ ) and fuzzy Negative-ideal solution (FNIS, $A^{-}$) can be defined as

$$
\begin{aligned}
& A^{+}=\left(\tilde{v_{1}^{+}}, \tilde{v_{2}^{+}}, \ldots, \tilde{v_{n}^{+}}\right) \\
& A^{-}=\left(\tilde{v_{1}}, \tilde{v_{2}}, \ldots, \tilde{v_{n}}\right)
\end{aligned}
$$

where,

$$
\tilde{v_{j}^{+}}=\max _{i}\left(v_{i j 4}\right) \text { and } \tilde{v_{j}^{-}}=\min _{i}\left(v_{i j 1}\right), i=1,2,3, \ldots, m, j=1,2,3, \ldots, n .
$$

The distance of each alternative (supplier selection criteria) from $A^{*}$ and $A^{*}$ can be currently calculated as

$$
\begin{aligned}
& d_{i}^{*}=\sum_{j=1}^{n} d\left(\tilde{V}_{i j}, \tilde{V}_{j}^{*}\right), i=1,2, \cdots, m \\
& d_{i}^{-}=\sum_{j=1}^{n} d\left(\tilde{V}_{i j}, \tilde{V}_{j}^{-}\right), i=1,2, \cdots, m
\end{aligned}
$$

where $d_{v}(.,$.$) is the distance measurement between two fuzzy numbers. A closeness coefficient is defined to$ determine the ranking order of all possible criteria based on supplier-selection once $d_{i}^{+}$and $d_{i}^{-}$of each vendor $A_{i}$ $(i=1,2,3, \ldots, m)$ has been calculated. The closeness coefficient $\left(C C_{i}\right)$ of each alternative (supplier selection criteria) is calculated as

$$
C C_{i}=\frac{d_{i}^{-}}{d_{i}^{*}+d_{i}^{-}}, i=1,2, \cdots, m
$$

According to the descending order of $C C_{i}$, a determination is made about the ranking order of all criteria used in the selection of suppliers. It found linguistic variables in evaluating the expert views within the framework of fuzzy logic to be a more realistic approach when determining the most important criteria leading to supplier selection. Thus, it was utilized from the decision rules of the five classes that were used in supplier evaluation and selection by Chen et al. (2006). (See Table 1.)

Table 1. Approval status of criteria leading to supplier selection

\begin{tabular}{ll}
\hline Closeness coefficient $\left(\mathrm{CC}_{\mathrm{i}}\right)$ & Assessment status \\
\hline $\mathrm{CC}_{\mathrm{i}} \boldsymbol{\epsilon}[\mathbf{0 , 0 . 2})$ & Do not recommend \\
$\mathrm{CC}_{\mathrm{i}} \boldsymbol{\epsilon}[\mathbf{0 . 2 , 0 . 4 )}$ & Recommend with high risk \\
$\mathrm{CC}_{\mathrm{i}} \boldsymbol{\epsilon}[\mathbf{0 . 4 , 0 . 6 )}$ & Recommend with low risk \\
$\mathrm{CC}_{\mathrm{i}} \boldsymbol{\epsilon}[\mathbf{0 . 6 , 0 . 8 )}$ & Approved \\
$\mathrm{CC}_{\mathrm{i}} \boldsymbol{\epsilon}[\mathbf{0 . 8 , 1 . 0 ]}$ & Approved and preferred \\
\hline
\end{tabular}




\section{Application}

A car company, Pars Khodro, that operates in Iran works with many suppliers in acquiring parts. The company was trying to determine the status of criteria leading to supplier selection within the twenty-three criteria determined by Dickson, as this manufacturing company desired to select an appropriate material supplier in order to purchase the key components of products. After introductory screening, it considered the criteria that five experts assessed as a way to handle these criteria used in the selection of suppliers. Accordingly, the twenty-three criteria identified by Dickson are as follows:

C1. Net price; includes discounts and freight charges offered by a supplier

C2. Quality; the capability of a supplier

C3. Delivery schedules

C4. Warranties and claims; policies of suppliers that are faced with a special situation

C5. Repair service

C6. Attitude; behavior toward the company purchasing from a supplier

C7. Aids; availability of educational courses in the use of products of a supplier

C8. Performance history

C9. Financial position

C10. Geographical location

C11. Future purchases; a supplier will offer a company

C12. Management and organization

C13. Communication system; associated with information, progress, and data about orders from a supplier.

C14. Technical capacity; includes research and development facilities of a supplier

C15. Production facilities and capacity

C16. Packaging; ability of a supplier to meet company requirements for a product

C17. Operational controls; includes reporting quality control and inventory control systems of a supplier.

C18. Amount of past business; the company has done with a supplier

C19. Position in the industry; includes production leadership and reputation of a vendor

C20. Compliance with company procedure; both bidding and operating by a vendor

$\mathrm{C} 21$. Impression; made by a supplier in personal contacts with the company

C22. Desire for company business; shown by a supplier

\section{C23. Labor relations record}

The decision matrix obtained by using the trapezoidal fuzzy numbers in Figure 1 by five experts working in the purchasing department of an automobile company operating in Iran was used to determine the status of criteria leading to supplier selection within the twenty-three criteria determined by Dickson (see Table 2)

Table 2. Fuzzy number values given by experts of the criteria used in supplier selection

\begin{tabular}{llllll}
\hline Criteria & Expert 1 & Expert 2 & Expert 3 & Expert 4 & Expert 5 \\
\hline C1 & $(0.7,0.8,0.8,0.9)$ & $(0.4,0.5,0.5,0.6)$ & $(0.2,0.3,0.4,0.5)$ & $(0.4,0.5,0.5,0.6)$ & $(0.9,0.9,1,1)$ \\
C2 & $(0.4,0.5,0.5,0.6)$ & $(0.7,0.8,0.8,0.9)$ & $(0.5,0.6,0.7,0.8)$ & $(0.5,0.6,0.7,0.8)$ & $(0.7,0.8,0.8,0.9)$ \\
C3 & $(0.9,0.9,1,1)$ & $(0.9,0.9,1,1)$ & $(0.9,0.9,1,1)$ & $(0.9,0.9,1,1)$ & $(0.9,0.9,1,1)$ \\
C4 & $(0.7,0.8,0.8,0.9)$ & $(0.7,0.8,0.8,0.9)$ & $(0.9,0.9,1,1)$ & $(0.9,0.9,1,1)$ & $(0.7,0.8,0.8,0.9)$ \\
C5 & $(0.4,0.5,0.5,0.6)$ & $(0.1,0.2,0.2,0.3)$ & $(0.1,0.2,0.2,0.3)$ & $(0.9,0.9,1,1)$ & $(0.7,0.8,0.8,0.9)$ \\
C6 & $(0.4,0.5,0.5,0.6)$ & $(0.1,0.2,0.2,0.3)$ & $(0.5,0.6,0.7,0.8)$ & $(0.5,0.6,0.7,0.8)$ & $(0.7,0.8,0.8,0.9)$ \\
C7 & $(0,0,0.1,0.2)$ & $(0,0,0.1,0.2)$ & $(0.1,0.2,0.2,0.3)$ & $(0.9,0.9,1,1)$ & $(0,0,0.1,0.2)$ \\
C8 & $(0.4,0.5,0.5,0.6)$ & $(0.7,0.8,0.8,0.9)$ & $(0.5,0.6,0.7,0.8)$ & $(0.5,0.6,0.7,0.8)$ & $(0,0,0.1,0.2)$ \\
\hline
\end{tabular}




\begin{tabular}{llllll}
\hline Criteria & Expert 1 & Expert 2 & Expert 3 & Expert 4 & Expert 5 \\
\hline C9 & $(0.4,0.5,0.5,0.6)$ & $(0,0,0.1,0.2)$ & $(0.4,0.5,0.5,0.6)$ & $(0.7,0.8,0.8,0.9)$ & $(0.4,0.5,0.5,0.6)$ \\
C10 & $(0.7,0.8,0.8,0.9)$ & $(0.7,0.8,0.8,0.9)$ & $(0.7,0.8,0.8,0.9)$ & $(0.9,0.9,1,1)$ & $(0.7,0.8,0.8,0.9)$ \\
C11 & $(0.7,0.8,0.8,0.9)$ & $(0.9,0.9,1,1)$ & $(0.9,0.9,1,1)$ & $(0.9,0.9,1,1)$ & $(0.7,0.8,0.8,0.9)$ \\
C12 & $(0.1,0.2,0.2,0.3)$ & $(0.4,0.5,0.5,0.6)$ & $(0.5,0.6,0.7,0.8)$ & $(0.7,0.8,0.8,0.9)$ & $(0.4,0.5,0.5,0.6)$ \\
C13 & $(0.1,0.2,0.2,0.3)$ & $(0.7,0.8,0.8,0.9)$ & $(0.7,0.8,0.8,0.9)$ & $(0.5,0.6,0.7,0.8)$ & $(0.5,0.6,0.7,0.8)$ \\
C14 & $(0,0,0.1,0.2)$ & $(0,0,0.1,0.2)$ & $(0.7,0.8,0.8,0.9)$ & $(0,0,0.1,0.2)$ & $(0.7,0.8,0.8,0.9)$ \\
C15 & $(0.7,0.8,0.8,0.9)$ & $(0.2,0.3,0.4,0.5)$ & $(0.5,0.6,0.7,0.8)$ & $(0.7,0.8,0.8,0.9)$ & $(0.4,0.5,0.5,0.6)$ \\
C16 & $(0.7,0.8,0.8,0.9)$ & $(0.4,0.5,0.5,0.6)$ & $(0.2,0.3,0.4,0.5)$ & $(0.9,0.9,1,1)$ & $(0.7,0.8,0.8,0.9)$ \\
C17 & $(0.1,0.2,0.2,0.3)$ & $(0.7,0.8,0.8,0.9)$ & $(0.5,0.6,0.7,0.8)$ & $(0.5,0.6,0.7,0.8)$ & $(0.1,0.2,0.2,0.3)$ \\
C18 & $(0.9,0.9,1,1)$ & $(0.9,0.9,1,1)$ & $(0.9,0.9,1,1)$ & $(0.7,0.8,0.8,0.9)$ & $(0.9,0.9,1,1)$ \\
C19 & $(0.1,0.2,0.2,0.3)$ & $(0.7,0.8,0.8,0.9)$ & $(0.9,0.9,1,1)$ & $(0.9,0.9,1,1)$ & $(0.1,0.2,0.2,0.3)$ \\
C20 & $(0.1,0.2,0.2,0.3)$ & $(0.4,0.5,0.5,0.6)$ & $(0.2,0.3,0.4,0.5)$ & $(0,0,0.1,0.2)$ & $(0.1,0.2,0.2,0.3)$ \\
C21 & $(0.9,0.9,1,1)$ & $(0,0,0.1,0.2)$ & $(0.7,0.8,0.8,0.9)$ & $(0.5,0.6,0.7,0.8)$ & $(0.2,0.3,0.4,0.5)$ \\
C22 & $(0.5,0.6,0.7,0.8)$ & $(0,0,0.1,0.2)$ & $(0.9,0.9,1,1)$ & $(0,0,0.1,0.2)$ & $(0.7,0.8,0.8,0.9)$ \\
C23 & $(0,0,0.1,0.2)$ & $(0.9,0.9,1,1)$ & $(0.2,0.3,0.4,0.5)$ & $(0.9,0.9,1,1)$ & $(0.1,0.2,0.2,0.3)$ \\
\hline
\end{tabular}

This is thought of as utility criteria, in which each expert created a normalized decision matrix, where $\tilde{x_{i j}}=\left(a_{i j}, b_{i j}, c_{i j}, d_{i j}\right) ; i=1,2, \ldots, 23$ (supplier selection criteria), $j=1,2, \ldots, 5$ (experts) are positive trapezoidal fuzzy numbers. Where $B$ is the sets of benefit criteria, for $\mathrm{j} \in \mathrm{B}, d_{j}^{+}=\max _{i} d_{i j}=1$ (see Table 2) is $\widetilde{r}_{i j}=\left(\frac{a_{i j}}{d_{j}^{*}}, \frac{b_{i j}}{d_{j}^{*}}, \frac{c_{i j}}{d_{j}^{*}}, \frac{d_{i j}}{d_{j}^{*}}\right)=\left(a_{i j}, b_{i j}, c_{i j}, d_{i j}\right)$ obtained.

From here, "the matrix in Table 2 is the same as the normalized decision matrix" and is subtracted to obtain the result. In addition, the experts' weights are the same, because they have an equal authority in the purchase department of this company. So, the weighted normalized fuzzy decision matrix is equal to the normalized decision matrix. Thus, the weighted normalized fuzzy decision matrix is seen in Table 2. According to the weighted normalized fuzzy decision matrix, a fuzzy positive-ideal solution (FPIS) and a fuzzy negative-ideal solution (FNIS) are obtained (see equations 6 and 7).

FPIS for each expert is as follows:

$$
A^{*}=[(1,1,1,1,),(1,1,1,1,),(1,1,1,1,),(1,1,1,1,),(1,1,1,1,)]
$$

FNIS for each expert is as follows:

$$
A^{-}=\left[\left(\begin{array}{llll}
0, & 0, & 0, & 0,
\end{array}\right),(0,0, \quad 0,0,),(0,0, \quad 0,0,),(0,0,0,0,),(0,0,0,0,)\right]
$$

The distances of each alternative (supplier selection criteria) from FPIS and FNIS with respect to each criterion (experts) were calculated as seen in Table 3. 
Table 3. Distances between supplier selection criteria and $A^{*}, A^{-}$with respect to each expert

\begin{tabular}{|c|c|c|c|c|c|c|c|c|c|c|}
\hline & $d_{i j}^{+}$ & & & & & $d_{i j}^{-}$ & & & & \\
\hline Criteria & Expert 1 & Expert 2 & Expert 3 & Expert 4 & Expert 5 & Expert 1 & Expert 2 & Expert 3 & Expert 4 & Expert 5 \\
\hline$\overline{\mathrm{C} 1}$ & 0.212 & 0.505 & 0.660 & 0.505 & 0.071 & 0.803 & 0.505 & 0.367 & 0.505 & 0.951 \\
\hline $\mathrm{C} 2$ & 0.505 & 0.212 & 0.367 & 0.367 & 0.212 & 0.505 & 0.803 & 0.660 & 0.660 & 0.803 \\
\hline $\mathrm{C} 3$ & 0.071 & 0.071 & 0.071 & 0.071 & 0.071 & 0.951 & 0.951 & 0.951 & 0.951 & 0.951 \\
\hline $\mathrm{C} 4$ & 0.212 & 0.212 & 0.071 & 0.071 & 0.212 & 0.803 & 0.803 & 0.951 & 0.951 & 0.803 \\
\hline $\mathrm{C} 5$ & 0.505 & 0.803 & 0.803 & 0.071 & 0.212 & 0.505 & 0.212 & 0.212 & 0.951 & 0.803 \\
\hline C6 & 0.505 & 0.803 & 0.367 & 0.367 & 0.212 & 0.505 & 0.212 & 0.660 & 0.660 & 0.803 \\
\hline $\mathrm{C} 7$ & 0.929 & 0.929 & 0.803 & 0.071 & 0.929 & 0.112 & 0.112 & 0.212 & 0.951 & 0.112 \\
\hline $\mathrm{C} 8$ & 0.505 & 0.212 & 0.367 & 0.367 & 0.929 & 0.505 & 0.803 & 0.660 & 0.660 & 0.112 \\
\hline C9 & 0.505 & 0.929 & 0.505 & 0.212 & 0.505 & 0.505 & 0.112 & 0.505 & 0.803 & 0.505 \\
\hline $\mathrm{C} 10$ & 0.212 & 0.212 & 0.212 & 0.071 & 0.212 & 0.803 & 0.803 & 0.803 & 0.951 & 0.803 \\
\hline C11 & 0.212 & 0.071 & 0.071 & 0.071 & 0.212 & 0.803 & 0.951 & 0.951 & 0.951 & 0.803 \\
\hline $\mathrm{C} 12$ & 0.803 & 0.505 & 0.367 & 0.212 & 0.505 & 0.212 & 0.505 & 0.660 & 0.803 & 0.505 \\
\hline $\mathrm{C} 13$ & 0.803 & 0.212 & 0.212 & 0.367 & 0.367 & 0.212 & 0.803 & 0.803 & 0.660 & 0.660 \\
\hline $\mathrm{C} 14$ & 0.929 & 0.929 & 0.212 & 0.929 & 0.212 & 0.112 & 0.112 & 0.803 & 0.112 & 0.803 \\
\hline $\mathrm{C} 15$ & 0.212 & 0.660 & 0.367 & 0.212 & 0.505 & 0.803 & 0.367 & 0.660 & 0.803 & 0.505 \\
\hline $\mathrm{C} 16$ & 0.212 & 0.505 & 0.660 & 0.071 & 0.212 & 0.803 & 0.505 & 0.367 & 0.951 & 0.803 \\
\hline $\mathrm{C} 17$ & 0.803 & 0.212 & 0.367 & 0.367 & 0.803 & 0.212 & 0.803 & 0.660 & 0.660 & 0.212 \\
\hline C18 & 0.071 & 0.071 & 0.071 & 0.212 & 0.071 & 0.951 & 0.951 & 0.951 & 0.803 & 0.951 \\
\hline C19 & 0.803 & 0.212 & 0.071 & 0.071 & 0.803 & 0.212 & 0.803 & 0.951 & 0.951 & 0.212 \\
\hline $\mathrm{C} 20$ & 0.803 & 0.505 & 0.660 & 0.929 & 0.803 & 0.212 & 0.505 & 0.367 & 0.112 & 0.212 \\
\hline $\mathrm{C} 21$ & 0.071 & 0.929 & 0.212 & 0.367 & 0.660 & 0.951 & 0.112 & 0.803 & 0.660 & 0.367 \\
\hline $\mathrm{C} 22$ & 0.367 & 0.929 & 0.071 & 0.929 & 0.212 & 0.660 & 0.112 & 0.951 & 0.112 & 0.803 \\
\hline $\mathrm{C} 23$ & 0.929 & 0.071 & 0.660 & 0.071 & 0.803 & 0.112 & 0.951 & 0.367 & 0.951 & 0.212 \\
\hline
\end{tabular}

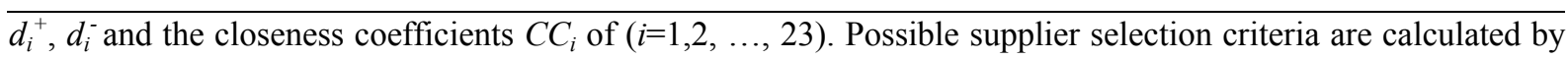
using equations 8,9 , and 10 (see Table 4).

Table 4. Computations $d_{i}^{+}, d_{i}^{-}$and the closeness coefficients $C C_{i}$

\begin{tabular}{llll}
\hline Criteria & $d_{i}^{+}$ & $d_{i}^{-}$ & $C C_{i}$ \\
\hline C1 & 1.952 & 3.132 & 0.616 \\
$\mathrm{C} 2$ & 1.664 & 3.430 & 0.673 \\
$\mathrm{C} 3$ & 0.354 & 4.757 & 0.931 \\
$\mathrm{C} 4$ & 0.778 & 4.312 & 0.847 \\
$\mathrm{C} 5$ & 2.394 & 2.684 & 0.529 \\
$\mathrm{C} 6$ & 2.255 & 2.839 & 0.557 \\
$\mathrm{C} 7$ & 3.660 & 1.499 & 0.291 \\
$\mathrm{C} 8$ & 2.381 & 2.739 & 0.535 \\
$\mathrm{C} 9$ & 2.430 & 0.478 \\
$\mathrm{C} 10$ & 0.656 & 4.164 & 0.819 \\
$\mathrm{C} 11$ & 0.619 & 4.460 & 0.875 \\
$\mathrm{C} 12$ & 2.393 & 2.685 & 0.529 \\
$\mathrm{C} 13$ & 1.962 & 3.137 & 0.615 \\
$\mathrm{C} 14$ & 3.210 & 1.942 & 0.377 \\
$\mathrm{C} 15$ & 1.956 & 3.138 & 0.616 \\
$\mathrm{C} 16$ & 1.659 & 3.430 & 0.674 \\
\hline
\end{tabular}




\begin{tabular}{llll}
\hline Criteria & $d_{i}^{+}$ & $d_{i}^{-}$ & $C C_{i}$ \\
\hline C17 & 2.553 & 2.546 & 0.499 \\
$\mathrm{C} 18$ & 0.495 & 4.608 & 0.903 \\
$\mathrm{C} 19$ & 1.960 & 3.130 & 0.615 \\
$\mathrm{C} 20$ & 3.699 & 1.408 & 0.276 \\
$\mathrm{C} 21$ & 2.239 & 2.893 & 0.564 \\
$\mathrm{C} 22$ & 2.508 & 2.638 & 0.513 \\
$\mathrm{C} 23$ & 2.533 & 2.594 & 0.506 \\
\hline
\end{tabular}

Approval status of criteria leading to supplier selection was utilized from the decision rules of the five classes that were used in supplier evaluation and selection by Chen et al. (2006) and is calculated in Table 1. Thus, as a result, approval status of supplier criteria according to Table 1 was made (see Table 5).

Table 5. Approval status of criteria leading to supplier selection

\begin{tabular}{lll}
\hline Criteria & $C C_{i}$ & Approval status \\
\hline C3 18 & 0.931 & \\
C11 & 0.903 & Approved and preferred \\
C4 & 0.875 & \\
C10 & 0.847 & \\
C16 & 0.819 & \\
C12 & 0.674 & \\
C15 & 0.673 & Approved \\
C1 & 0.616 & \\
C13 & 0.616 & \\
C19 & 0.615 & \\
C21 & 0.615 & \\
C6 & 0.564 & \\
C8 & 0.557 & \\
C12 & 0.535 & \\
C5 & 0.529 & Recommend with low risk \\
C22 & 0.529 & \\
C23 & 0.513 & \\
C17 & 0.506 & \\
C9 & 0.499 & \\
C14 & 0.478 & \\
C7 & 0.377 & \\
C20 & 0.291 & \\
\hline
\end{tabular}

According to Table 5, there are not any supplier selection criteria in assessment status "Do not recommend" for this automobile firm operating in Iran. Criteria in the first two classes of assessment status, determined by Chen et al., are important for the company. Therefore, supplier selection criteria that are important for the automobile firm are respectively, delivery, the amount of past business, reciprocal arrangements, warranties, geographical location, packaging ability, quality, production facilities and capacity, net price, communication system, and reputation and position in the industry. 


\section{Conclusions}

Administrators working in the purchasing department in a car company, Pars Khodro, that operates in Iran have thought that establishing supplier selection criteria and developing supplier involvement programs would create an environment based on trust that builds prolific relationships with suppliers and increase communication. Therefore, the supplier selection criteria process became the most important issue in terms of the company for a successful supply chain system application. It is intended to guide administrators through the TOPSIS method, which is a multi-criteria decision technique, in order to determine leading criteria for selecting the most suitable suppliers.

Supply chain management processes generally are connected to imprecise and uncertain data, and fuzzy-set theory that is associated with them. The use of linguistic variables is highly useful in a decision making process that performance values cannot be expressed by means of numerical values. In other words, it is suitable to use linguistic variables instead of numerical values for assessing possible suppliers with respect to criteria and important weights. An extended version of TOPSIS in a fuzzy environment is submitted with this article because the decision-makers' feelings, experience, and subjective judgments often appear in the process of supplier selection process. The twenty-three criteria determined by Dickson for this manufacturing company were used to select a suitable material supplier in order to purchase main components of products. Afterward, it was considered as the criteria for five experts to use when making an assessment about using these criteria in the selection of suppliers.

In addition, the fuzzy TOPSIS method is very useful. According to the closeness coefficient, one can specify not only the ranking order, but also the assessment status of all feasible alternatives. Thus, the proposed method provides more objective information for supplier selection and assessment in a supply chain system. According to the results obtained, the most important supplier criteria for the company have been identified as delivery, amount of past business, reciprocal arrangements, warranties, and geographical location, rather than price, which was expected to be an important criterion. If a company takes into account these criteria for its supplier selection, it can make rational decisions. The systematic framework for the supply chain management process in a fuzzy situation presented in this article can be easily extended to the analysis of other management decision processes. Thus, a combined single solution can be found. In addition, it can be varied with the solution using different fuzzy member functions. As a result, improving the approach for solving and expanding a group decision support system in a fuzzy situation can be intended as a topic for future research.

\section{References}

Bellman, R. E., \& Zadeh, L. A. (1970). Decision-making in a fuzzy environment. Management Science, 17(4), B-141-B-164. Retrieved http://dx.doi.org/10.1287/mnsc.17.4.B141 from http://www.jstor.org/stable/2629367

Buckley, J. J. (1985). Fuzzy hierarchical analysis. Fuzzy sets and systems, 17(3), 233-247. http://dx.doi.org/10.1016/0165-0114(85)90090-9

Büyüközkan, G., Feyzioğlu, O., \& Nebol, E. (2008). Selection of the strategic alliance partner in logistics value chain. International Journal of Production Economics, 113(1), 148-158. http://dx.doi.org/10.1016/j.ijpe.2007.01.016

Chai, J., Liu, J. N., \& Ngai, E. W. (2012). Application of decision-making techniques in supplier selection: A systematic review of literature. Expert Systems with Applications, 40(10), 3872-3885. http://dx.doi.org/10.1016/j.eswa.2012.12.040

Chen, C. T. (2000). Extensions of the TOPSIS for group decision-making under fuzzy environment. Fuzzy sets and systems, 114(1), 1-9. http://dx.doi.org/10.1016/S0165-0114(97)00377-1

Chen, C. T. (2001). A fuzzy approach to select the location of the distribution center. Fuzzy sets and systems, 118(1), 65-73. http://dx.doi.org/10.1016/S0165-0114(98)00459-X

Chen, C. T., Lin, C. T., \& Huang, S. F. (2006). A fuzzy approach for supplier evaluation and selection in supply chain management. International Journal of Production Economics, 102(2), 289-301. http://dx.doi.org/10.1016/j.ijpe.2005.03.009

Delgado, M., Herrera, F., Herrera-Viedma, E., \& Martínez, L. (1998). Combining numerical and linguistic information in group decision making. Information Sciences, 107(1), 177-194. http://dx.doi.org/10.1016/S0020-0255(97)10044-5

Delgado, M., Verdegay, J., \& Vila, M. (1992). Linguistic decision-making models. International Journal of Intelligent Systems, 7(5), 479-492. http://dx.doi.org/10.1002/int.4550070507 
Dickson, G. W. (1966). An analysis of vendor selection systems and decisions. Journal of purchasing, 2(1), 5-17. Retrieved from http://www.ism.ws/pubs/JournalSCM/jscmarticle.cfm?ItemNumber=7222

Dobler, D. W., Burt, D. N., \& Lee, L. (1990). Purchasing and materials management: Text and cases. McGraw-Hill New York.

Herrera, F., \& Herrera-Viedma, E. (1996). A model of consensus in group decision making under linguistic assessments. Fuzzy sets and Systems, 78(1), 73-87. http://dx.doi.org/10.1016/0165-0114(95)00107-7

Herrera, F., \& Herrera-Viedma, E. (2000). Linguistic decision analysis: Steps for solving decision problems under linguistic information. Fuzzy Sets and systems, 115(1), 67-82. http://dx.doi.org/10.1016/S0165-0114(99)00024-X

Hsu, H. M., \& Chen, C. T. (1997). Fuzzy credibility relation method for multiple criteria decision-making problems. Information Sciences, 96(1), 79-91.

Kahraman, C., Ates, N. Y., Çevik, S., Gülbay, M., \& Erdogan, S. A. (2007). Hierarchical fuzzy TOPSIS model for selection among logistics information technologies. Journal of Enterprise Information Management, 20(2), 143-168. http://dx.doi.org/10.1108/17410390710725742

Kaufmann, A., Gupta, M. M., \& Kaufmann, A. (1985). Introduction to fuzzy arithmetic: Theory and applications. Van Nostrand Reinhold Company New York.

Li, C., Fun, Y., \& Hung, J. (1997). A new measure for supplier performance evaluation. IIE transactions, 29(9), 753-758. http://dx.doi.org/10.1080/07408179708966385

Negi, D. S. (1989). Fuzzy analysis and optimization, Ph.D. Thesis, Department of Industrial Engineering, Kansas State University.

Paksoy, T., Pehlivan, N. Y., \& Kahraman, C. (2012). Organizational strategy development in distribution channel management using fuzzy AHP and hierarchical fuzzy TOPSIS. Expert Systems with Applications, 39(3), 2822-2841. http://dx.doi.org/10.1016/j.eswa.2011.08.142

Schmitz, J., \& Platts, K. (2004). Supplier logistics performance measurement: Indications from a study in the automotive industry. International Journal of Production Economics, 89(2), 231-243. http://dx.doi.org/10.1016/S0925-5273(02)00469-3

Vonderembse, M. A., \& Tracey, M. (1999). The impact of supplier selection criteria and supplier involvement in manufacturing performance. Journal of Supply Chain Management, 35(3), 33-39. http://dx.doi.org/10.1111/j.1745-493X.1999.tb00060.x

Wang, T. C., \& Chang, T. H. (2007). Application of TOPSIS in evaluating initial training aircraft under a fuzzy $\begin{array}{lllll}\text { environment. Expert } & \text { Systems with }\end{array}$ http://dx.doi.org/10.1016/j.eswa.2006.07.003

Weber, C. A., Current, J. R., \& Benton, W. (1991). Vendor selection criteria and methods. European journal of operational research, 50(1), 2-18. http://dx.doi.org/10.1016/0377-2217(91)90033-R

Xia, W., \& Wu, Z. (2007). Supplier selection with multiple criteria in volume discount environments. Omega, 35(5), 494-504. http://dx.doi.org/10.1016/j.omega.2005.09.002

Yahya, S., \& Kingsman, B. (1999). Vendor rating for an entrepreneur development programme: A case study using the analytic hierarchy process method. Journal of the Operational Research Society, 50, 916-930.

Zadeh, L. A. (1965). Fuzzy sets. Information and control, 8(3), 338-353. Retrieved from http://www-bisc.cs.berkeley.edu/Zadeh-1965.pdf http://dx.doi.org/10.1016/S0019-9958(65)90241-X

Zadeh, L. A. (1975). The concept of a linguistic variable and its application to approximate reasoning-I. Information sciences, 8(3), 199-249. http://dx.doi.org/10.1016/0020-0255(75)90036-5

Zimmermann, H. J. (2001). Fuzzy set theory-and its applications. Springer. http://dx.doi.org/10.1007/978-94-010-0646-0

\section{Copyrights}

Copyright for this article is retained by the author(s), with first publication rights granted to the journal.

This is an open-access article distributed under the terms and conditions of the Creative Commons Attribution license (http://creativecommons.org/licenses/by/3.0/). 